\title{
Estácio de Sá e a fundação do Rio de Janeiro
}

Elysio BELCHIOR*

Resumo: $\mathrm{O}$ artigo aborda a presença de Estácio de Sá no Rio de Janeiro, bem como a sua fundação e a expulsão dos franceses, que chegaram aqui sob o comando de Villegagnon, em 1555, formando a França Antártica. Discute a participação da armada de Estácio de Sá na guerra contra os tamoios e tupiniquins em São Vicente, a fim de conseguir recursos humanos e mantimentos para retornar à luta na Guanabara. Por fim, questiona se Estácio de Sá teria sido governador ou somente capitão da cidade de São Sebastião do Rio de Janeiro.

Palavras-Chave: Colonização Francesa; França Antártica; Villegagnon; Estácio de Sá.

Nossa exposição versa sobre a presença de Estácio de Sá no contexto de um dos eventos significativos para o processo de formação do Brasil, ocorrido há quatrocentos e cinqüenta anos, dos quais, duzentos e sessenta e sete antes mesmo do advento do Brasil-Nação.

O evento não teve curta duração, prolongando-se como unidade de compreensão desde 1555, com a chegada de Villegagnon à Guanabara, determinado a instalar a França Antártica, até o definitivo malogro, em 1567, dessa experiência

* Sócio titular do Instituto Histórico e Geográfico Brasileiro; emérito do IHGH do Rio de Janeiro; colaborador do Colégio Brasileiro de Genealogia; correspondente do IHGB do Uruguai; correspondente da Academia Nacional de História da Argentina; correspondente da Real Academia da História da Espanha e da Associação de Diplomados da Escola Superior de Guerra. E-mail: belchiorelysio@de.cnc.com.br 
colonial, mescla de refúgio religioso, empreendimento mercantil e ponto estratégico no caminho marítimo para as Índias, capítulo da expansão da Europa Ocidental, nascida dos descobrimentos ibéricos. Durante 12 anos, perdurou o desafio lançado a Portugal, contestando-lhe o direito de posse de terras do Mundo Novo e águas do mar oceano. Os portugueses aceitaram, responderam e venceram o pleito, que teve como principal resultado a fundação da Cidade de São Sebastião do Rio de Janeiro. Cidade que foi o ponto focal da atuação de Estácio de Sá nos últimos anos de sua vida.

Não é de hoje que se reconhece a importância desta contenda. Mem de Sá, que lhe foi contemporâneo e protagonista, tão pronto reduziu a escombros o Forte de Coligny e deu fim à efêmera Henriville, em 1560, escreveu à rainha regente de Portugal, D. Catarina d'Áustria, instando se povoasse o Rio de Janeiro, para segurança de todo o Brasil (1).

Varnhagen, passados trezentos anos, ressaltou os esforços das capitanias, então existentes, "contra o inimigo comum, esforços que eram novos elementos que iam estreitar, pelos laços do coração, a futura unidade brasileira" (2). De fato, aos portugueses que vieram do Reino com o propósito de enfrentar franceses e tamoios uniram-se, pela primeira vez, os moradores das capitanias de Pernambuco, Bahia, Porto Seguro, Ilhéus, Espírito Santo e São Vicente, na primeira ação bélica para garantir a futura integridade da América Portuguesa e dos frutos que dela poderiam advir. Nos tempos atuais, Vasco Mariz frisa que o fim da França Antártica frustrou os planos de Villegagnon de expulsar os portugueses do Brasil (3).

Visto que não faltava o pensamento dos jesuítas, de ação marcante nos primórdios do Brasil, o padre Manuel da Nóbrega, em 1560, julga necessário "povoar-se o Rio de Janeiro e fazer-se nela outra cidade como a da Bahia porque com ela ficará tudo guardado, assim como a capitania de São Vicente como a do Espírito Santo" (4). No século XX, o padre Serafim Leite mantém a visão estratégica de Nóbrega ao afirmar que se o quisto representado pela França Antártica não fosse extirpado a tempo, 
"teria impedido a unidade do Brasil (5)". Para outro jesuíta, também da nossa época, Domingos Maurício Gomes dos Santos, as duas metades do Brasil "separadas pelo bisturi traiçoeiro das incursões francesas ressoldaram-se para reconstituir indissoluvelmente a unidade geográfica, político-social e religiosa da Terra de Vera Cruz" (6).

Ressaltando o aspecto religioso, e não apenas profano, que presidiu a atuação dos discípulos de Loiola nos episódios do Rio de Janeiro, e a narração que deles fizeram, tem-se, em 1565, o Pe. Quiricio Caxa, o qual considerava que a conquista do Rio de Janeiro "abriu grande porta para ser o Reino de Portugal acrescentado em o temporal e espiritual".

Ao rememorarmos Estácio de Sá, não pretendemos desmerecer nem Mem de Sá, o Afonso Henriques das terras brasileiras, no dizer de Oliveira Martins, e consolidador da cidade do Rio de Janeiro, nem o Padre Manuel da Nóbrega, a quem o Rio de Janeiro deve, segundo testemunhou Anchieta, "conselhos, ajuda e fervor", nos momentos decisivos que antecederam a fundação da cidade. Também são dignos de memória capitães e soldados, moradores, humildes ou não, religiosos ou leigos, cujos nomes podem ser encontrados, notadamente, em documentos da época e, ao lado deles, a legião anônima dos guerreiros do Araribóia e dos que vieram para a cidade trazendo esperanças de vida nova, e para sempre se foram no silêncio dos papéis perdidos ou das lápides sepulcrais partidas.

Pelo muito que fizeram por São Sebastião do Rio de Janeiro, cabe dedicar-lhes o apelo de Anchieta para que se tivesse "particular memória dos que residem e ao diante residirão nesta nova povoação oferecidos a tantos perigos, da qual se espera haver de nascer muito fruto para a gloria do Senhor e a salvação das almas"(7). $\mathrm{Na}$ impossibilidade de rememorar todos, julgamos bem representá-los o Cavaleiro Fidalgo da Casa de Elrei Nosso Senhor, Estácio de Sá, capitão da armada que veio fundar a cidade de São Sebastião, dela primeiro capitão, um dos poucos a contribuir com a vida e a morte, para as três etapas da conquista e povoamento do Rio de Janeiro, centralizadas em 
torno dos anos de 1560, 1565 e 1567. E agiu de tal forma que mereceu de Joaquim Veríssimo Serrão o oportuno juízo de que a Estácio de Sá coube "o decisivo impulso para a conquista do sítio e pacificação da terra. Foi graças ao seu esforço e dos primeiros moradores que se puderam assentar os fundamentos da nova cidade"(8). Não lhe negaram reconhecimento os que com ele conviveram, nem recompensas os que nele confiaram. Os pósteros, por vezes, o esqueceram, mas não faltaram aqueles que o cercaram de uma aura de heroísmo, ou em versos cantaram seus feitos e destino. No rastro destas divergências, originaram-se dúvidas que abordaremos.

Estácio de Sá chegou de Portugal em 1557, acompanhando Mem de Sá, substituto de Duarte da Costa como terceiro governador-geral do Brasil. Mem de Sá sempre o tratou como sobrinho, embora os genealogistas ainda discutam sobre sua ascendência familiar. Sua idade não é conhecida com exatidão, e a incerteza que disto resulta, por vezes, o atinge em desabono, quando lhe negam maturidade e qualidades indispensáveis aos cargos e missões que desempenhou.

Capistrano de Abreu, em carta a João Lúcio de Azevedo, de 19 de dezembro de 1917 (9), indaga-lhe, em tom de dúvida, acerca do que constava no manuscrito publicado no Arquivo Bibliográfico da Universidade de Coimbra (1904 e sgts), segundo o qual Estácio de Sá teria apenas 17 anos quando governou o Rio de Janeiro. Trata-se do manuscrito De algumas coisas mais notáveis do Brasil e de alguns costumes dos índios, com justos argumentos atribuído ao jesuíta Francisco Soares e elaborado entre os anos 1591/1594 (10). Em tal documento, consta idade que o bom senso rejeita, pois se a tivesse, em 1559, ao ser nomeado capitão da galé Conceição, teria tão-somente 11 anos (11). No extremo oposto, é conhecido o resultado do exame osteológico feito em seus restos mortais exumados da sepultura em que jaziam na antiga Igreja de São Sebastião, do Morro do Castelo, em 16 de novembro de 1862, e a ela depois restituídos. D. Pedro II, presente ao ato, registrou em seu Diário que o Dr. Bernardo de Sousa Fontes, futuro Visconde de Sousa Fontes, professor de Anatomia da Faculdade de Medicina, lhe dissera na 
ocasião, tratar-se de ossos de um homem com menos de 40 anos. O laudo final do exame, assinado também pelo Dr. Francisco Ferreira de Abreu, depois Barão de Teresópolis, professor de Medicina Legal do mesmo estabelecimento de ensino, estimou a idade entre os limites de 35 e 50 anos (12). A versão mais corrente é a de que na época de seu engajamento nas ações da Guanabara, Estácio de Sá estivesse com idade ao redor de 30 anos.

Pertenceria, portanto, à faixa etária de Pedro Álvares Cabral quando deixou o Restelo, em 1500, no comando da maior armada que até então largara velas de Portugal para ir às Índias, levando, além da tripulação dos barcos, cerca de 1.500 homens de guerra. E de Martim Afonso de Souza, que aos 30 anos, veio correr as costas do Brasil, em 1530, com suas naus e caravelas, combateu entrelopos que infestavam o litoral, estacionou três meses no Rio de Janeiro, nele edificou casa forte, construiu dois bergantins, e de torna-viagem do Sul, onde fora em busca das águas do Rio da Prata, pacificamente fundou, em 1532, a Vila de São Vicente, a primeira do Brasil.

A idade de 30 anos não era, portanto, inibitória a feitos ilustres.

A participação de Estácio de Sá nos acontecimentos da Guanabara iniciou-se em 1560, o que nos leva a esboçar o encadeamento dos fatos que o conduziram ao desempenho das missões que lhe foram atribuídas.

Tomé de Sousa, visitando a Guanabara em 1553, sugeriu se fizesse em suas margens uma povoação "honrada e boa" para conter a constante presença dos franceses em rendoso escambo com os indígenas que habitavam as aldeias das redondezas da Baía. Todavia, nada foi feito e a chegada de Villegagnon com os primeiros colonos para povoarem a França Antártica, em 1555, agravou a situação, a ponto de os moradores de São Vicente se queixarem dos prejuízos que lhes causavam os incômodos vizinhos, capturando-lhes até embarcações.

Apesar das reclamações, três anos depois ainda se desconhecia o real poder que a Antártica França dispunha para alcançar e manter seus objetivos, tanto era assim que Mem de 
Sá em $1^{\circ}$ de junho de 1558, quando corria a costa do Brasil, escreveu do Espírito Santo à regente D. Catarina, comunicando ter despachado duas embarcações para "ver se podiam tomar alguma chalupa das que eles [franceses] trazem pela costa para se saber bem a verdade de quanta gente é, o que fazem ou o que determinam"(13). Mas já admitia tivessem o propósito de se tornarem fortes, possuindo muita gente bem armada.

Somente no ano seguinte, Mem de Sá, por outros meios e com mais detalhes, tomou conhecimento da verdadeira extensão do perigo que a ocupação estrangeira da Guanabara representava para a integridade do Brasil em mãos portuguesas. É o que se deduz da conversa mantida, em Ilhéus, com um trânsfuga da França Antártica, quando terminada a campanha conduzida contra os indígenas locais, o governador-geral preparava-se para deixar a capitania. Carta do padre Francisco Pires, sem data, mostra que o encontro foi antes de 21 de julho de 1559, visto que já se referia à volta do governador-geral a Salvador, nesse dia.

Mem de Sá no Instrumento de serviços, documento judicial de 1570, assim o descreve:

"Ao tempo que me queria partir dos Ilhéus veio da capitania de São Vicente um gentil-homem francês que se chamava monsenhor de Bolés, pessoa de sangue segundo os franceses afirmavam, o qual viera de França para povoar o Rio de Janeiro onde estava outro fidalgo monsenhor de Vila Ganhão que tinha feito uma fortaleza muito forte e por desavenças que com ele teve se saiu de sua companhia e se foi para São Vicente e daí veio ter comigo e me descobriu algumas ruins intenções de Vila Ganhão em prejuízo desta terra e do serviço de Sua Alteza" (14).

Somente se descobre o que ainda não se conhece.

O jejum de informações sobre a colônia francesa da Guanabara e os termos da conversa com João de Bolés sugerem que somente em meados de 1559, Mem de Sá ficou ciente que os franceses tinham por comandante um fidalgo, não dos muitos 
que na França havia, mas um famoso vice-almirante da Bretanha, chamado Nicolau Durand de Villegagnon, formado nas letras e na experiência de uma vida aventurosa, cavaleiro de Malta aos 21 anos, corajoso, elogiado aos 31 anos por atos de bravura em combates na África do Norte, dono de respeitável folha de serviços prestados ao seu país. Ao mesmo tempo, está claro na entrevista que o fundador da França Antártica ainda permanecia na Guanabara, e disto inteirou-se o governadorgeral. Ambos não poderiam saber, porém, que o vice-almirante estava prestes a se retirar para a Europa, decisão concretizada em outubro de 1559. Diante disto, a afirmação de Gaffarel de que Mem de Sá somente se abalou a atacar a colônia francesa da Guanabara depois de conhecer a partida de Villegagnon para a Europa, não se ajusta à realidade dos fatos (15).

As intenções de Villegagnon reveladas pelo desertor evidenciaram-se na carta dirigida a el-rei, por Mem de Sá, em 13 de junho de 1560, dando-lhe conta que o fidalgo francês pretendia ao viajar para a Europa, de lá trazer "gente e naus para ir esperar as de Vossa Alteza que vêm da Índia e destruir ou tomar todas essas capitanias e fazer-se um grande senhor"(16), e se isto porventura se materializasse, e o Rio de Janeiro voltasse a ser ocupado pelos franceses, é ainda Mem de Sá quem afirma, "hei medo que seja verdade o que o Vila Ganhão dizia, que todo o poder de Espanha nem do Grão Turco o poderia tomar"(17). O padre Manuel da Nóbrega, a quem Mem de Sá certamente confiou o teor das intenções de Villegagnon, escreveu ao Cardeal Infante D. Henrique, alertando-o de que se o vice-almirante francês não conseguisse auxílio na França, entender-se-ia com o sultão da Turquia "prometendo-lhe de lhe dar por esta parte a conquista da Índia e as naus portuguesas que de lá viessem, porque poderia aqui fazer o turco suas armadas com a muita madeira da terra"(18).

Com a chegada do Reino, em fins de novembro de 1559, da armada sob o comando de Bartolomeu Vasconcelos da Cunha, enviada com a finalidade de correr a costa do Brasil, Mem de Sá decidiu que melhor seria partir direto para o Rio de Janeiro sem gastar tempo e monção com outros objetivos. A expedição saiu 
de Salvador com destino ao Rio de Janeiro em 16 de janeiro de 1560, chegando à Guanabara em 21 de fevereiro de 1560.

Mem de Sá não encontrou mais Villegagnon, e disto somente soube quando a nau Isaura apresou um navio pertencente ao próprio vice-almirante francês, que já estava na Europa, deixando em seu lugar o sobrinho Bois-le-Comte. As intensas hostilidades, com baixas para ambas as partes duraram três dias. Naturalmente, existem dos combates as versões dos vencedores e dos vencidos. Mas não há dúvidas de que o resultado favoreceu os portugueses, ao ser o Forte de Coligny abandonado pela guarnição depois de tomado o depósito de munições e a caixa d’água.

Quando os atacantes desembarcaram na ilha de Serigipe, o primeiro a nela por o pé foi Estácio de Sá, e o segundo Gaspar Leitão, ambos dignos de recompensas "para exemplo dos homens desta terra", consoante extrato da carta de Mem de Sá, de 22 de setembro de 1560, feito por Gaspar Álvares Louzada, existente na Biblioteca Municipal de Santarém (19). Estácio de Sá recebeu a recompensa sugerida, tanto que no dia 3 de janeiro de 1561, em Salvador, quando compareceu, como testemunha, no processo instaurado por heresia, contra monsenhor de Bolés, o escrivão qualificou o depoente como Cavaleiro Fidalgo da Casa de El-rei Nosso Senhor"(20).

Obtida a vitória, Mem de Sá em conselho com os capitães, ordenou a destruição do Forte de Coligny, na Ilha de Serigipe, por lhe faltarem meios para ocupá-lo, e, ao retirar-se para São Vicente, deixou espalhados pelos arredores da Guanabara remanescentes da França Antártica, em convívio com os indígenas.

Estácio de Sá, do Rio de Janeiro seguiu o mesmo rumo, partindo em seguida para Portugal, permanecendo lá por cerca de três anos. Regressou ao Brasil no comando de dois galeões para com eles participar da conquista e povoação do Rio de Janeiro.

Nesse tempo, o Rio de Janeiro voltara a ser ponto de partida de incursões de tamoios e franceses que chegavam até São Vicente. Brás Cubas, em carta a el-rei, de 25 de abril de 
1562, solicitou o envio de bombardeiros e pólvora, necessários à defesa da capitania contra tais ataques. Pedia também que mandasse povoar o Rio de Janeiro, para que "não haja franceses que favoreçam estes contrários que são muito nossos vizinhos porque os franceses lhes dão muitas armas de fogo e muita pólvora com que lhes dão muito ânimo para cometerem o que quiserem como fazem".(21) Entretanto o apelo demorou ainda três anos para ser atendido, até que o governador-geral em janeiro de 1564, "por o gentio do Rio de Janeiro não ficar de todo pacífico mandou uma armada bem pequena para tornar ao Rio de Janeiro"(22), e impossibilitado de ir em pessoa, designou Estácio de Sá, capitão-mor, e Brás Fragoso, ouvidor geral. Estácio de Sá partia para o Rio de Janeiro para enfrentar forças cujo poderio não conhecia, comandando uma "bem pequena armada", deficiência comprovada, no próprio teatro da luta.

O capitão-mor alcançou a Guanabara em fevereiro de 1564, depois de dois meses de combates com incertos resultados, já com a presença de Manuel da Nóbrega e José de Anchieta, por sugestão do tio, chamados de São Vicente com o propósito de pacificar os tamoios do Rio de Janeiro - como já tinham feito em Ubatuba -, partiram os navios de Estácio de Sá para São Vicente, no Dia de Páscoa, 2 de abril, em demanda de reforços humanos e mantimentos. Durou quase um ano a estada de Estácio de Sá naquela capitania, em virtude de acontecimentos inesperados, capazes de comprometer o êxito da campanha para manter a presença portuguesa na Guanabara, mas, ao mesmo tempo, mostraram quão valiosa foi a união de propósitos e esforços entre o capitão-mor e o padre Manuel da Nóbrega.

José de Anchieta, na carta ao Padre Diogo de Mirão, de 9 de julho de 1565, resume as dificuldades encontradas ao informá-lo das

"muitas contradições assim dos povos de São Vicente, como dos capitães e gente da armada, aos quais parecia impossível povoar-se o Rio de Janeiro com tão pouca gente e mantimentos, o capitão-mor Estácio de Sá e o ouvidor-geral Brás Fragoso que sempre resistiram a todos estes encontros e contradições 
determinaram levar a cabo esta empresa que tinham começado" (23).

O Apóstolo do Brasil, que presenciou as discordâncias, certificava por escrito, perante seu superior em Lisboa, a determinação de Estácio de Sá de cumprir as reais ordens sobre o que fazer no Rio de Janeiro. De todas as divergências, as que mais o preocuparam e aumentaram o sentimento de responsabilidade quanto ao êxito da missão recebida, nasceram de duas decisões da Câmara Municipal de São Paulo de Piratininga, as quais refletiam a conjuntura desfavorável que a Capitania de São Vicente atravessava. Para superá-las, Estácio de Sá precisava de vivência do ambiente político e social da terra em que se encontrava, o que Manuel da Nóbrega poderia oferecer-lhe, como de fato proporcionou.

O ouvidor-geral Braz Fragoso, ao chegar a São Vicente, baixou Provisão requisitando, sob pena de multa, farinha e bois para reabastecimento da armada. Consoante ata de 29 de abril de 1564, os oficiais da Câmara de São Paulo responderam-lhe que não tinham condições de atender ao pedido de farinha, porquanto a produção atrasara-se muito, prejudicada por vários fatores, sobressaindo-se a epidemia de varíola que vitimara moradores, e fabricá-la demandaria tempo. No tocante ao gado, seus donos também não poderiam cumprir a Provisão que os mandava levar os animais até o litoral para pesagem e pagamento. Pobres, as despesas de viagem estavam além de suas posses. Contudo, não se negariam obedecê-la, caso alguém ecebesse os bois no planalto (24).

Menos de uma quinzena depois, em Resolução de 12 de maio de 1564 (25), os vereadores representaram perante Estácio de Sá de que não deveria deixar a Capitania, sem que antes empregasse a gente de sua armada na guerra contra os tamoios e tupiniquins, assaltantes contumazes da vila, com grande prejuízo dos moradores. Caso não cumprisse a Resolução, seria responsabilizado pelo abandono de São Paulo e perda do Mosteiro da Companhia de Jesus, que tantos frutos oferecia à comunidade local. E por tudo isto teria que prestar contas a 
Deus e a el-rei. Todavia, se atendesse à Câmara, os moradores estariam prontos para o ajudarem com suas pessoas, fazenda e tudo o mais necessário para a guerra. No fundo, para duas guerras: a de São Paulo de Piratininga e a do Rio de Janeiro. Permeando estas inesperadas dificuldades, havia o descontentamento que lavrava na armada e a má vontade da população em reforçá-la com homens e flecheiros indígenas.

Em suma, caso o capitão-mor não atendesse à exigência dos vereadores, dificilmente conseguiria recursos humanos e mantimentos, ficando prejudicada, senão impossibilitada, a missão ao Rio de Janeiro. Acatando-a, incorreria em falta ao empregar e arriscar os comandados em ação não prevista nas ordens reais que recebera.

Manuel da Nóbrega, que sempre se empenhara na fundação do Rio de Janeiro, instando-a junto a el-rei, pela segurança que representava para a capitania de São Vicente e consciente do quanto esta, por seu turno, significava para o sucesso da conquista e povoamento do Rio de Janeiro, decerto apoiava a decisão da Câmara Municipal de São Paulo de Piratininga, tanto mais que sempre procurou preservar e engrandecer a vila, que o tem como seu fundador.

É com base nesta alternativa criada pela decisão dos vereadores que se deve entender o divulgado diálogo entre Estácio de Sá e Manuel da Nóbrega, ocorrido logo após a chegada da armada a São Vicente. Estácio teria dito:"Padre Nóbrega! E que conta darei a Deus e a el-rei se deitar a perder esta armada?, a que Nóbrega respondera: "Eu darei conta a Deus de tudo, e se for necessário irei à presença de el-rei e responderei por vós"(26). O diálogo não poderia ter ocorrido nas vésperas da partida da armada de volta ao Rio de Janeiro, pois então já se encontrava dotada dos reforços fornecidos pelos moradores de São Vicente, entre eles Jorge Ferreira e Heliodoro Eobanos. Recorda-se que tanto a pergunta de Estácio de Sá, quanto a resposta de Manuel da Nóbrega giravam em torno da responsabilidade perante Deus e el-rei, invocada na representação de 12 de maio. 
Feitas as pazes com os indígenas, como nos conta Frei Vicente Salvador, o fim das contradições, a tranqüilidade de São Paulo e o reforço da armada confirmam como foram fundamentais para o sucesso da fundação do Rio de Janeiro os esforços conjugados entre Estácio de Sá e Manuel da Nóbrega. Simão de Vasconcelos salienta-os ao se referir às cartas que ambos escreveram a Mem de Sá, ainda em 1564, dizendo que nelas "o sobrinho relatava o muito que tinha obrado o Padre e o Padre o muito que tinha obrado o sobrinho, e ambos convinham em como estavam remediadas as faltas da armada, que partiria a seu intento, contentes os soldados e com esperança de vitória" (27).

Partiu Estácio de Sá para o Rio de Janeiro, em meados de janeiro de 1965, levando cerca de 200 homens. Entre eles, quem primeiro assinara a representação de 12 de maio de 1564, o presidente da Câmara Municipal da Vila de São Paulo de Piratininga, juiz ordinário Antônio de Mariz, que se fixou no Rio de Janeiro, onde faleceu vítima de flechas indígenas. Entre as sesmarias que possuiu, Salvador Correia de Sá lhe concedera, em 1569, a Ilha de Vira Galhão.

Os passos iniciais da Cidade de São Sebastião do Rio de Janeiro, ao sopé do Pão de Açúcar, na esplanada entre este penedo e o Morro Cara de Cão, Anchieta os narrou na carta ao Pe. Diogo de Mirão, de 9 de julho de 1565. Localização indicada no mapa atribuído a Luís Teixeira, c. 1586, encontrado por Norival de Freitas, em 1907, na Biblioteca da Ajuda, quando ali pesquisava documentos sobre a história do Brasil, por iniciativa do Instituto Histórico e Geográfico Brasileiro.

No dia $1^{\circ}$ de março, data fixada em razão da cronologia constante da carta de Anchieta, os pioneiros da cidade do Rio de Janeiro, após o desembarque

\footnotetext{
"começaram a roçar em terra com grande fervor e cortar madeira para a cerca, sem querer saber dos tamoios nem dos franceses, mas como quem entrava em sua terra, e se foi logo o capitão-mor dormir em terra e dando ânimo aos outros para fazer o mesmo, ocupado cada um em fazer o que lhe era ordenado por ele" (28).
} 
Madeira, terra e pedras para a fortificação eram carregadas nos ombros "sem haver quem a isso repugnasse, desde o capitão-mor até o mais pequeno"(29). No dia 6 de março, travaram-se os primeiros combates, e ciladas foram armadas; quatro dias depois, a própria cerca, ainda incompleta, recebeu ataque direto dos tamoios, com muita luta desbaratados. Uma nau francesa foi capturada e libertada após a retirada de canhões e munição.

Aos poucos, durante quase dois anos, debaixo de tiros e flechas ervadas, sob o governo do capitão-mor Estácio de Sá, a cidade constituiu-se formalmente, com a instalação da Câmara Municipal, sob a presidência do juiz ordinário Pedro Martins Namorado; procedeu-se à criação e o preenchimento dos cargos indispensáveis ao funcionamento da administração pública; tabeliães e escrivães tiveram fé pública; oficializou-se o selo das armas da cidade, entregue ao seu guardião; instituiu-se o patrimônio territorial da cidade; sesmaram-se terras; completouse a cerca fortificada; ergueu-se a primeira capela consagrada a São Sebastião, padroeiro da cidade, aos cuidados de sua confraria.

Grandes foram os perigos e trabalhos. Além da fome, a prolongada ausência de suas fazendas nas capitanias de origem poderia generalizar o sentimento de desamparo e gerar desânimo,

"se não fosse o capitão-mor - registra José de Anchieta - amigo de Deus e afável, que nunca descansa de noite e de dia, acudindo a uns e a outros sendo o primeiro nos trabalhos e todos terem grande e certa confiança que Sua Alteza proverá, tanto que souber estar feito pé no Rio de Janeiro, que tão temeroso era" (30).

El-rei admitiu Estácio de Sá, ainda na cidade de São Sebastião, como noviço, na Ordem de Cristo, pela Carta Régia de 8 de março de 1566, reconhecendo D. Sebastião que o conquistador do Rio de Janeiro poderia ainda "fazer muitos serviços a Nosso Senhor, e a mim e aos Reis destes reinos 
governadores e perpétuos administradores da dita Ordem"(31). O fato de o rei ter dispensado Estácio de Sá do cumprimento das formalidades probatórias necessárias ao ingresso na Ordem de Cristo ressalta sobremodo a alta consideração que o monarca atribuiu ao feito de Estácio de Sá no Rio de Janeiro e a existência de dificuldades naturais que o capitão-mor enfrentaria para cumprir tais formalidades à risca, antecipadamente.

Quatro meses depois de fundada a cidade, o padre Quiricio Caxa, em carta ao provincial dos jesuítas em Portugal, de 13 de julho de 1565, louvou Estácio de Sá, afirmando que

\begin{abstract}
"se os merecimentos dos Capitães fazem alguma coisa para serem ajudados e favorecidos nas coisas árduas e grandes que empreendem em serviço de seu Senhor e Rei, os de Estácio de Sá são tais quais convêm a um Capitão afamado por sua prudência e siso para determinar-se quando há de acometer-se e seu ânimo e constância para acometer e levar adiante o determinado (32).
\end{abstract}

A fase final do processo de fundação da Cidade do Rio de Janeiro iniciou-se em 19 de janeiro de 1567, quando o governador-geral Mem de Sá chegou à Guanabara no comando de uma armada, cujo núcleo formaram os navios vindos do Reino sob o comando de Cristóvão de Barros, futuro capitão da cidade. Viera para continuar o povoamento e a edificação da cidade de São Sebastião, que seu sobrinho iniciara dois anos antes, e concluir a expulsão dos remanescentes da França Antártica. No dia seguinte ao da chegada, travou a primeira batalha na região de Uruçumirim, ou seja, nas proximidades do atual Morro da Glória, e poucos dias depois destruiu a aldeia de Paranapuan, na ilha do Maracaiaguaçu, hoje Governador, e, por fim, sem luta, caiu o último reduto contrário. Cerca de um ano depois, Mem de Sá declarou que terminara de povoar e edificar a Cidade de São Sebastião, transferindo-a para o Morro do Castelo, e que "a terra estava em paz e sossego e tirados os franceses que nela havia". Esse sucesso, todavia, custou a vida de Estácio de Sá, morto em conseqüência de ferimento sofrido no rosto, durante a batalha de Uruçumirim. Seu corpo, sepultado na primitiva capela da várzea 
do Cara de Cão, depois transportado para a Igreja de São Sebastião, no alto do Morro do Castelo, ali permaneceu até a demolição da colina, iniciada em 1922. Atualmente, repousa da Igreja do santo padroeiro da cidade, na Tijuca.

Não são muitas, pelo mundo, as cidades, várias vezes centenárias, cujo túmulo do fundador pode ser visitado. Varnhagen reconhece que

"a sepultura do primeiro capitão-mor do Rio de Janeiro é para o Brasil uma venerável relíquia, que não só a piedade, mas também a gratidão, nos impõe o dever de acatar como um herói mártir, que sacrificou sua existência pelo País, que hoje se deve gloriar de proclamá-lo seu cidadão adotivo"(33).

Corroborando o testemunho de José de Anchieta, sobre a fundação da cidade de São Sebastião do Rio de Janeiro em $1^{\circ}$ de março de 1565, a existência da cidade reflete-se em um dos primeiros documentos que lhe dizem respeito. Trata-se da carta de sesmaria dada a Pedro Rodrigues, em 6 de setembro de 1565, na qual Estácio de Sá a concede como "capitão-mor da armada que El-Rei Nosso Senhor mandou correr esta costa do Brasil e povoar o dito Rio de Janeiro, onde ora está fazendo fortaleza em nome do dito Senhor e Capitão desta dita Cidade de São Sebastião (34)". É interessante notar que a sesmaria abrangia uma ilha defronte da região de Meresgitiba, de localização hoje incerta, "que é donde traziam madeira quando se queria povoar a IIha de Virgalhão", provavelmente a primeira menção em português do novo nome da Ilha de Serigipe, que permanece até nossos dias, recordando a presença de Villegagnon no Rio de Janeiro.

Mem de Sá, em 20 de setembro de 1565, na qualidade de governador-geral do Brasil, nomeou Pedro da Costa, tabelião do público e judicial, e escrivão das sesmarias, tendo em vista "se achar comigo na tomada do Rio de Janeiro e o fazer de sua pessoa mui valentemente, assim no edificamento da cidade de São Sebastião que o capitão-mor Estácio de Sá fez no dito Rio de Janeiro"(35). Isto foi escrito quando a cidade ainda se 
encontrava na várzea da Cara de Cão. Já no Morro do Castelo, Mem de Sá, ao prover Francisco Dias Pinto no cargo de alcaidemor em 15 de agosto de 1567, nomeou-o em razão deste já ter servido a el-rei, inclusive desde que o mandara "na companhia do capitão-mor Estácio de Sá povoar e edificar a cidade de São Sebastião do Rio de Janeiro"(36). Como se observa, Mem de Sá afirma que seu sobrinho fez, edificou e povoou a cidade de São Sebastião do Rio de Janeiro.

Não obstante estas explícitas referências à fundação e ao fundador da cidade, registraram-se dúvidas quanto a tais pontos. O próprio Padre José de Anchieta, apesar de presenciar o início da cidade, diz na Informação da Província do Brasil, de 1585, que a cidade chama-se "de São Sebastião, que fundou elrei D. Sebastião, de boa memória, que ele determinava fazer muito nobre por ser de seu nome e a primeira que havia fundado"(37). O padre Francisco Soares, no manuscrito sobre "as coisas notáveis do Brasil", também adota a mesma posição em favor do jovem e infortunado soberano português. Mas há quem atribua a Mem de Sá a fundação do Rio de Janeiro por dois motivos. O primeiro, porque Estácio de Sá viera a seu mandado fazer a cidade do Rio de Janeiro, assim como D. Sebastião o fizera em posição decisória de nível mais elevado. Mas, tirante este argumento, invoca-se a favor de Mem de Sá, a declaração contida em sua provisão nomeando Salvador Correia de Sá, capitão da cidade e governador da capitania do Rio de Janeiro, que viera "povoar este Rio de Janeiro e edificar esta cidade de São Sebastião. No mesmo sentido, Mem de Sá declarou no Instrumento de Serviços (38) que depois de decidida a luta no Rio de Janeiro, em 1567, e ouvidos os capitães e outras pessoas, escolhera um sítio no alto do morro, que veio a ser chamado do Castelo, para edificar a cidade de São de Sebastião. Estaria Mem de Sá contradizendo o que três anos antes afirmara em documento de fé pública, ou seja, que Estácio de Sá edificara a cidade de São Sebastião? E cinco anos após ter dito que o sobrinho fizera a cidade? A idéia de uma nova cidade nasceu mais das declarações das testemunhas convocadas para confirmarem o que Mem de Sá dissera no requerimento inicial do 
Instrumento de Serviços, muitas das quais falaram por ouvir dizer, visto que não estiveram no Rio de Janeiro. Um dos poucos depoentes que acompanharam Mem de Sá em sua viagem, em 1567, o bispo Pedro Leitão, afirmou que o governador-geral mudara a antiga São Sebastião. A cidade velha deixou de existir fisicamente, visto que em 1574, o local onde a edificaram foi incluído na sesmaria dada por Cristóvão de Barros ao juiz do peso do pau brasil, Crispim da Cunha.

Vale notar que a continuidade da cidade de São Sebastião fundada por Estácio de Sá, em $1^{\circ}$ de março de 1565, e transferida por Mem de Sá para o Morro do Castelo, em data incerta, é atestada por documentos quinhentistas. É o caso da Carta Anua, do Padre Francisco Gonçalves, enviada em 22 de abril de 1568 à Província Toletana e Aragonesa, da Companhia de Jesus, na qual explicitamente registra que estava o governador-geral Mem de Sá, no Rio de Janeiro "acabando a cidade de S. Sebastião, a qual, depois de vencer os Brasis e Franceses que ali havia e feitas pazes, mudou para outro lugar mais forte e mais acomodado"(39). Trata-se de documento sem outro intuito senão o de informar um fato testemunhado, e refletia o pensamento dos contemporâneos sobre o que presenciaram. O mesmo ocorre em uma carta de sesmaria, passada em favor de residentes, atendendo a requerimento por eles feito a Salvador Correia de Sá, em 1578, quando a cidade já estava no Morro do Castelo. No preâmbulo, da carta o escrivão declara que a lavrara "em esta cidade de São Sebastião do Rio de Janeiro", pedida por moradores "nesta dita cidade", tendo recebido despacho do Capitão "deste dito Rio de Janeiro", atendendo aos requerentes, "moradores nesta cidade", no qual alegaram "que eles são dos primeiros povoadores que vieram ajudar a povoar esta dita cidade, dês o tempo de Estácio de Sá"(40). Portanto, sentiam e pensavam os moradores, ser a cidade em que viviam, nos altos do Morro do Castelo, a mesma que muitos vieram fazer e para tanto bateram-se em companhia do capitão-mor Estácio de Sá.

Em documentos subscritos por Estácio de Sá, ou nos quais é mencionado, quando a ele se referem, qualificam-no como capitão da Cidade de São Sebastião do Rio de Janeiro. Mem de 
Sá também é mencionado como capitão da cidade de Salvador de Todos los Santos. Teria sido Estácio de Sá governador da cidade que fundara? Quando o historiador Roberto de Macedo escrevia o livro Cidade do Rio de Janeiro - Fundação e Primeiros Governadores, em bilhete enviado a um advogado, formulou a seguinte indagação: "Estácio nomeou servidores, concedeu patrimônio territorial à cidade, instituiu-lhe o brasão cívico. Documentação incontroversa. Em face do exposto, deve ou não ser ele incluído na relação dos Governadores, embora não se lhe conheça título de nomeação? Ignoramos a resposta, mas na lista dos governadores, encontra-se registrado que na data de $1^{\circ}$ de março de 1565, "o capitão-mor da armada começa a governar com o título de Capitão, a cidade de São Sebastião do Rio de Janeiro, que veio fundar para conquista e povoamento da Guanabara" (41). O título usado por Estácio de Sá encontra justificação na distinção feita na Carta Régia de 7 de julho de 1549, que nomeou o primeiro governador-geral do Brasil. Diz ela que Tomé de Sousa exerceria o cargo de capitão da povoação e terras da dita Baía de Todos os Santos; de governador da dita Capitania, e o de governador-geral das outras Capitanias e terras da Costa do dito Brasil (42). Ora, Estácio de Sá só poderia ser capitão da cidade que veio povoar, e não governador do Rio de Janeiro, uma vez que a cidade localizava-se na Capitania doada a Martim Afonso de Sousa, que tinha seu próprio governador. A Capitania do Rio de Janeiro somente foi criada como capitania real em 1567. Por isso Mem de Sá, ao nomear o sobrinho Salvador Correia de Sá para substituir o fundador e primeiro capitão, nomeou-o "Capitão e Governador desta dita cidade e Capitania toda deste Rio de Janeiro".

O padre Antônio Vieira, no sermão pregado em 1655, na Capela Real de Lisboa ensinou que "o semeador e o pregador é nome, o que semeia e o que prega é ação, e as ações são as que dão o ser ao pregador. Ter nome de pregador, ou ser pregador de nome, não importa nada: as ações, a vida, o exemplo, as obras são as que convertem o mundo"(43). Estácio de Sá com o nome de capitão governou a cidade de São Sebastião do Rio de Janeiro. Pouco importa o nome. Com obras, exemplos, ações e 
vida destacou-se no evento em que se deu a conversão do Rio de Janeiro francês no Rio de Janeiro luso-brasileiro.

BELCHIOR, Elysio. Estácio de $\mathrm{Sa}$ and the founding of Rio de Janeiro. História, v.27, n.1, p. 77-100, 2008.

\begin{abstract}
The article deals with Estacio de Sa's presence in Rio de Janeiro as well as its foundation and the expulsion of the French that arrived here under the command of Villegagnon in 1555 having established the French Antarctic. It argues the participation of the Estacio de Sa armada in the war against the tamoios and tupiniquins in Sao Vicente, which had the purpose of obtaining human resources and supplies to return to the struggle in Guanabara. In the end, it questions as to whether Estacio de Sa had been governor or only captain of the city of Sao Sebastiao in Rio de Janeiro.
\end{abstract}

Keywords: French Colonization; French Antarctic; Villegagnon; Estacio de Sa.

\title{
REFERÊNCIAS BIBLIOGRÁFICAS
}

ABREU, Capistrano de - Capítulos de História Colonial: 1500-1800, Rio de Janeiro, 4a. ed., Briguiet, 1954, .

ABREU, Capistrano de - Correspondência de Capistrano de Abreu, Rio de Janeiro, Inst. Nacional do Livro, 1954/i956, 3. v.

ANCHIETA, José de - Cartas, informações, fragmentos históricos e sermões, Rio de Janeiro, Academia Brasileira de Letras, 1933.

ARQUIVO MUNICIPL DE SÃO PAULO - Actas da Câmara da Villa de S. Paulo (1562-1296), Duprat, 1914.

ARQUIVO NACIONAL - Tombo das Cartas de Sesmarias do Rio de Janeiro, 1594-1595; 1602=1605, Rio de Janeiro, Arq. Nacional, 1967. BELCHIOR, Elysio de Oliveira - Conquistadores e povoadores do Rio de Janeiro - Rio de Janeiro, Liv. Brasiliana, 1965. 
BELCHIOR, Elysio de Oliveira - Ainda conquistadores e povoadores do Rio de Janeiro, Rio de Janeiro, Rev. do IHGB, v. 402, jan/mar., 1999, [49-98].

BELCHIOR, Elysio de Oliveira - O Rio de Janeiro e a formação nacional, Rio de Janeiro, Rev. do IHGB, v. 408, jul/set., 2000, [225-237].

BIBLIOTECA NACIONAL - Documentos Históricos, Tombo das cartas de sesmarias do Rio de Janeiro d por Cristóvão de Barros (1573-1574), dadas por Salvador Correia de Sá (1578-1579).Biblioteca Nacional, v. CXI., 1997.

BIBLIOTECA NACIONAL - Documentos relativos a Mem de Sá, governador-geral do Brasil, Rio de Janeiro Anais da Biblioteca Nacional,, v. 27, 1905, [127-280]

Cartas jesuíticas avulsas, 1550-1568 - Rio de Janeiro, Academia Brasileira de Letras, $2^{\mathrm{a}}$ ed., 1931.

CORTESÃO, Jaime - A fundação de São Paulo - Capital geográfica do Brasil, Rio de Janeiro, Livros de Portugal, 1955.

CORTESÃO, Jaime - Pauliceae Lusitana Monumenta Historica, Lisboa, Real Gabinete Português de Leitura, 1956, 3 v.

DIAS, Carlos Medeiros (org.) - História da Civilização Portuguesa do Brasil, Porto, Lito. Nacional, 1921/1924, 3 v.

Documentos relativos à exumação dos ossos de Estácio de Sá, feito por deliberação do IHGB, Rio de Janeiro, Rev. Do IHGB, n. 26, 1863, (301316]

FERREIRA, João da Costa - A cidade do Rio de Janeiro e seu termo, Rio de Janeiro, Imprensa Nacional, 1933.

FERREIRA, Tito Lívio - Nóbrega e Anchieta em São Paulo de Piratininga, São Paulo, Casper Libero, 1953.

FRAGOSO, Augusto Tasso - Os franceses no Rio de Janeiro. Rio de Janeiro, Biblioteca do Exército, 2004.

Fundação da Cidade do Rio de Janeiro, Rio de Janeiro. Rev. do IHGB, v. 276, jul/set.1967, [227-306].

GAFFAREL, Paul - Histoire du Brésil Français au seizième siécle, Paris, Maisonneuve, 1878.

LEITE, Serafim - História da Companhia de Jesus no Brasil, Lisboa/Rio de Janeiro, Livr. de Portugal/Inst. Nac. do Livro, 1933/1950, 10 v. LEITE, Serafim - Cartas do Brasil e mais escritos do Pe. Manuel da Nóbrega, Coimbra, Univ. de Coimbra, 1955.

LEITE, Serafim - Suma histórica da Companhia de Jesus no Brasil, Lisboa, Junta de Investigações Ultramarinas, 1965. 
MACEDO, Roberto - Cidade do Rio de Janeiro: fundação e primeiros governadores -1565-1783, Rio de Janeiro, DASP, 1967.

MACEDO, Roberto - Estácio de Sá, Rio de Janeiro, Rev. do IHGB, v. 138, jan/mar., 1983, [281-282].

MARIZ, Vasco - Villegagnon: vilão ou herói? Rio de Janeiro, R. do IHGB, n. 404, jul.set. 1999.

MARIZ, Vasco - Ensaios históricos, Rio de Janeiro, Barléus, 2004. MARIZ, Vasco e PROVENÇAL, Lucien - Villegagnon e a França Antártica, Rio de Janeiro, Nova Fronteira, 2000.

MARIZ, Vasco - A Fundação do Rio de Janeiro: Gonçalo Coelho, Villegagnon ou Estácio de Sá?, n. 41, 2002, [49=55]

MARQUES, Manuel Eufrásio de Azevedo - Apontamentos históricos, geográficos, biográficos, estatísticos e noticiosos da Província de São Paulo, Belo Horizonte, Itatiaia, 1980, 2 v.

MELLO, Carlos Egberto H. Vieira de - O Rio de Janeiro no Brasil quinhentista, São Paulo, Giordano, 1996

MENDONÇA, Paul Knauss - O Rio de Janeiro da Pacificação, Rio de Janeiro, Prefeitura da Cidade do Rio de Janeiro, 1991.

NEME, Mário - Notas de revisão da História de São Paulo, século XVI, São Paulo, Anhambi, 1959.

NÓBREGA, Manuel da - Cartas do Brasil, Rio de Janeiro, Academia

Brasileira de Letras, 1931.

ORCIUOLI, Henrique - Estácio na Guanabara, Rio de Janeiro, Biblioteca do Estado da Guanabara, [s.d.].

PEDRO II, Diário do imperador D. Pedro II, Petrópolis, Anuário do Museu Imperial, v. XVII, 1956, [7-319].

PIRES FILHO, A. Teixeira - Um capítulo da História Carioca: o local do desembarque de Villegaignon, Rio de Janeiro. Rev. Marítima Brasileira, v. 1/3, ano LXXXV, jan/mar., 1966 [55-71].

PREFEITURA MUNICIPAL DO DISTRITO FEDERAL - Ordens e

Provizoens Reays, Rio de Janeiro, 1928-1929, 2 v.

Processo de João de Bolés e justificação requerida pelo mesmo, Rio de Janeiro, Anais da Biblioteca Nacional, v. 25, 1903, [21-308];

PROVENÇAL, Lucien, e MARIZ, Vasco - Villegagnon, un Chevalier de Malta au Brésil, Paris, Rive Droit, 2001.

SALVADOR, Vicente - História do Brasil, São Paulo, Weisflog, 1918. SANMARTIN, Giulio - Cidade do Rio de Janeiro: curiosidades na história de sua fundacão, Rio de Janeiro, G. Sanmartin, 1998. 
SANTOS, Domingos Maurício Gomes dos - Manuel da Nóbrega, grande empresário espiritual do Brasil, Lisboa, Panorama, n. 33/34, 4a. série, mar/jun, 1970, [36-43]

SERRÃO, Joaquim Veríssimo - O Rio de Janeiro no século XVI, Lisboa, Comissão Nacional das Comemorações do IV Centenário do Rio de Janeiro, 1965, 2 v.

SOARES, Francisco, Coisas notáveis do Brasil, Rio de Janeiro, Inst. Nac. do Livro, v. 1, 1966.

TROTTA, Frederico - A fundação da Cidade do Rio de Janeiro, Rio de Janeiro, Pref. Distrito Federal, , s.d.

VARNHAGEN, Francisco Adolfo - História Geral do Brasil, São Paulo, $5^{\mathrm{a}}$ ed., Melhoramentos, s.d, 5 v.

VASCONCELOS, Simão de - Crônica da Companhia de Jesus,

Petrópolis, Vozes, 1977, 2 v.

VIEIRA, Antônio - Sermões, Porto, Lello, 1959, 5 v.

WETZEL, Herbert Ewaldo - Mem de Sá: Terceiro governador-geral do Brasil, (1557-1570), Rio de Janeiro, Cons. Federal de Cultura, 1972.

\section{NOTAS}

1 CORTESÃO, Jaime, (1956), v. 1, p. 290

2 VARNHAGEN, F. Adolfo, (s.d.), v. 5, p. 370.

3 MARIZ, (1999), p. 646.

4 LEITE, Serafim, (1955), p. 369.

5 LEITE, Serafim, (1955), p. 234.

6 SANTOS, Domingos M.G., (1970), p. 38.

7 ANCHIETA, José, (1933), p. 254.

8 SERRÃO, José Veríssimo, (1965), v. 1, p. 93.

9 ABREU, Capistrano de, (1954/6), v. 2, p. 78

10 Também publicado na Revista do Instituto Histórico e Geográfico Brasileiro, em 1923.. e pelo Instituto Nacional do Livro, em edição crítica, de 1966.

11 MACEDO, Roberto, (1983), p. 281.

12 PEDRO II, (1956), 266; Doc. Relativos à exumação,1863, p.301

13 CORTESÃO, Jaime, 1956, 1 v. p. 284.

14 BIBLIOTECA NACIONAL, (1905) p. 134.

15 GAFFAREL, Paul, (1878), p. 298.

16 CORTESÃO, Jaime, (1956), v. 1, p. 290.

17 CORTESÃO, Jaime, (1956), v. 1290.

18 LEITE, Serafim, (1955), p. 369. 
19 SERRÃO, Joaquim Veríssimo, (1965), v. 1, p. 76.

20 Processo de João de Boles, (1903), p. 219.

21 CORTESÃO, Jaime, (1956), v. 1, p. 357.

22 BIBLIOTECA NACIONAL, (1905), p. 35.

23 ANCHIETA, José de, (1933), p. 245.

24 ARQUIVO MUNICIPAL DE SÃO PAULO, (1914), V. 1, p. 41

25 ARQUIVO MUNICIPAL DE SÃO PAULO, (1914), V. 1, p. 42

26 LEITE, Serafim, (1965), p. 34

27 VASCONCELOS, Simão de, (1977), v. 2, p. 114.

28 ANCHIETA, José de, (1933), p. 249.

29 ANCHIETA, José de, (1933), p.249.

30 ANCHIEA, José de (1933), p. 253.

31 SERRÃO, Joaquim Veríssimo, (1965). V. 2, p. 54.

32 CARTAS AVULSAS, $(1931)<$ p. 454.

33 VARNHAGEN, F. Adolfo (s.d.), v. 5, p. 388/9.

34 PREF. D. FEDERAL, (1928), p.34.

35 PREF. D. FEDERAL (1928), p. 5.

36 PREF. D. FEDERAL, (1928), p. 20.

37 ANCHIETA, José de, (1933), p. 419.

38 BIBLIOTECA NACIONAL, (1905), P.143/4

39 CARTAS AVULSAS, (1931), p. 490/1;

.40 BIBLIIOTECA NACIONAL, (1997), P. 143.

41 MACEDO, Roberto, (1967), p. 81.

42 DIAS, Carlos Malheiros, (1922/4), v. 3, p. 334/5.

43 VIEIRA, Antônio, Sermões, 1959, v. 1, p. 14.

Artigo recebido em 03/2008. Aprovado em 07/2008.

HISTÓRIA, São Paulo, 27 (1): 2008 
